Formaldehyde Induced Fluorescence (F.I.F.)

Fixation:

Quench small pieces of tissue $(1-4 \mathrm{~mm})$ in iso-pentane cooled with liquid nitrogen. Transfer to a freeze dryer or store the frozen tissue in liquid nitrogen in the refrigerator. Freeze dry tissue overnight at $-60^{\circ} \mathrm{C}$.

Freeze-dried tissue is then transferred to a closed box of about 1 litre capacity containing $5.0 \mathrm{~g}$ paraformaldehyde with some moisture present. The moisture is insured by a very light misting of water onto the powder surface, prior to placing the slides in the box containing paraformaldehyde powder.

Making sure the lid is tightly sealed, place the container in an oven at $60^{\circ} \mathrm{C}$ for 1 to 3 hours.

Sections:

Remove the tissue from container after fixation. Do not open the container until you have it under a hood, since it will contain formaldehyde gas.

Use fresh paraformaldehyde for each freeze-dried specimen.

Vacuum-embed the freeze-dried tissue in paraffin wax for approximately 1 hour.

Some scientists prefer to use a paraffin wax with the addition of a high concentration of plastic poylmer as an aid to thin sectioning. Sections are cut at 6 to $8 \mu \mathrm{m}$ and mounted on Fisher Superfrost/Plus slides.

Method:

After drying the sections in the oven, dewax the sections in xylene and mount in a suitable mounting medium. Examine sections with the fluorescent microscope using BG38, UG1 and barrier filters.

Results:

Bioactive amines such as 5-hydroxytryptamine, dopamine, adrenalin, noradrenaline and histamine - bright yellow fluorescence.

Reference:

Falck,B. \& Owman,C. (1965) Acta Univ. Lund., Sect., II, No.7

Eric C. Kellar, University of Pittsburgh Medical Center

\section{Tips On Finding A Good Etchant For Metals}

Start with a handbook of chemistry and physics. In the tables of physcial constants will be listed the metals solubilities in various acids. Pick an appropriate acid, and as a first try use $10 \%$ acid in methanol (a good electrical conductor). Ethanol is less conductive and more viscous than methanol. Always check chemical safety before starting. Never mix nitric acid with ethanol, for example; it explodes above a $5 \%$ concentration. Chill the solvent to at least $0^{\circ} \mathrm{C}$ before adding acid.

Refinements may start with adjusting the etching bath temperature to $0^{\circ} \mathrm{C}$ or $-45^{\circ} \mathrm{C}$. Also, 2 to $5 \%$ butyl cellusolve may improve the polishing film, assisting the preservation of precipitates and boundaries, while smoothing the matrix.

An example:

Etching copper from cobalt may be possible with a $3-5 \%$ mixture of nitric acid in methanol or water. Try using the mixture at room temperature; if the action is too slow, increase the acid concentration.

This approach may work because copper is dissolved by nitric acid (and electropolished by mixtures containing nitric acid). The CRC Handbook lists cobalt as soluble in acids, but with no specifics. Electropolishing mixtures for cobalt contain percholric acid, not nitric. So, nitric acid may have little effect on cobalt, and dissolve copper.

Another approach to etching is to use a non-acid electrolyte.
I have developed one called BK-2. This solution does not cause hydride formation in materials initially free of hydride. (It doesn't work on copper, however.)

This solution is less hazardous than the usual perchoric acid solution, and generally does not attack dislocations around large precipitates, unlike acid electrolytes. This attack usually causes the loss of the precipitate from the sample, as the surrounding matrix is etched away.

BK-2 is made as follows.

$5.3 \mathrm{~g} \mathrm{LiCl}$

$11.16 \mathrm{~g} \mathrm{Mg}\left(\mathrm{ClO}_{4}\right)^{2}$

$100 \mathrm{~mL}$ butyl cellusolve

$500 \mathrm{~mL}$ methanol

Try using in a single-jet electo-polishing unit at $-50^{\circ}$ to $60^{\circ} \mathrm{C}$ and 80 to $200 \mathrm{~V}, 15-20 \mathrm{~mA}$, with slow to medium electrolyte flow through the nozzle. depending on the sample.

A difficult sample of Al with 6 wt- $\%$ Ge, furnace aged to grow large precipitates was thinned by the above solution, to which had been added $200 \mathrm{~mL}$ glacial acetic acid. Thinning was done at $-25^{\circ} \mathrm{C}, 100 \mathrm{~V}$, and $15 \mathrm{~mA}$ in a single-jet electro-polisher.

Kestel, B.J., 1986, Non-acid electrolyte thins many materials for TEM without causing hydride formation. Ultramicroscopy 19:205-212.

Bernard Kestel, Argonne National Laboratory

\section{Changes in Fluorescence Spectra of the Dye FM 1-43 in Different Environments}

I have measured fluorescence spectra of FM 1-43 in a variety of environments. In water (or $0.1 \mathrm{M}$ salt. or $0.1 \mathrm{M}$ salt $+1 \%$ Bovine Serum Albumin or $0.1 \mathrm{M}$ salt $+0.5 \%$ C12E $9 \neq$ ), the emission spectrum is very broad with an approximately symmetrical peak centered at $648 \mathrm{~nm}$. Ouantum yield is low.

When the dye is allowed to partition to a polar-nonpolar interface, and the aqueous dye is either given very small room in which to maneuver (a hydrocarbon-water emulsion) or is removed (like washing externally labeled cells with dyefree buffer), the spectrum becomes polychromatic, indicating creation of the emission dipole by a change in rotation/ vibration/excitation modes of the molecule. i.e., the 2 rings become coplanar with the styryl linker as the molecule lays at the interface. The largest amplitude peak then is at $593 \mathrm{~nm}$ (measured with $0.25 \mathrm{~nm}$ bandpass). Quantum yields jump by a factor of 10 to 40 times depending on the wavelength.

So the upshot is that aqueous dye is redder than interfacial dye and dye in vesicles is a mix of both. However, I calculated based on the interfacial energy of FM 1-43 that about $98 \%$ of the dye in a $60 \mathrm{~nm}$ diameter endosome or synaptic vesicle is sitting at the membrane (it doesn't partition into the membrane).

$¥ 1$ have also used nonspecific rat ( $\mathrm{gG}$ ). C12E9 is a polyoxyethylene ether nonionic detergent made by Calbiochem.

Walter Niles University of Illinois College of Medicine

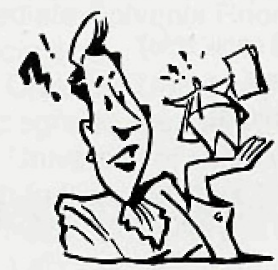

